\title{
A Patient Safety Toolkit for Family Practices
}

\author{
Stephen M. Campbell, PhD, *†+ Brian G. Bell, PhD, $\S$ Kate Marsden, MS, $\S$ Rachel Spencer, BM BS, $\S$ \\ Umesh Kadam, PhD,// Katherine Perryman, PhD, * Sarah Rodgers, PhD, $\$$ Ian Litchfield, PhD, $\mid$ \\ David Reeves, PhD, $\dagger$ Antony Chuter, BT, ** Lucy Doos, PhD, 9 Ignacio Ricci-Cabello, PhD, †† \\ Paramjit Gill, DM, $₫$ Aneez Esmail, PhD, † Sheila Greenfield, PhD, 9 Sarah Slight, PhD, $\dagger$ Karen Middleton, $\$ \$$ \\ Jane Barnett, BSc, \&\$ Michael Moore, BS,//// Jose M. Valderas, PhD, $9 / 1$ \\ Aziz Sheikh, MD, *** and Anthony J. Avery, $D M^{*} \xi$
}

Objective: Major gaps remain in our understanding of primary care patient safety. We describe a toolkit for measuring patient safety in family practices. Methods: Six tools were used in 46 practices. These tools were as follows: National Health Service Education for Scotland Trigger Tool, National Health Service Education for Scotland Medicines Reconciliation Tool, Primary Care Safequest, Prescribing Safety Indicators, Patient Reported Experiences and Outcomes of Safety in Primary Care, and Concise Safe Systems Checklist.

Results: Primary Care Safequest showed that most practices had a welldeveloped safety climate. However, the trigger tool revealed that a quarter of events identified were associated with moderate or substantial harm, with a third originating in primary care and avoidable. Although medicines reconciliation was undertaken within 2 days in more than $70 \%$ of cases, necessary discussions with a patient/carer did not always occur. The prescribing safety indicators identified 1435 instances of potentially hazardous prescribing or lack of recommended monitoring (from 92,649 patients). The Concise Safe Systems Checklist found that $25 \%$ of staff thought that their practice provided inadequate follow-up for vulnerable patients discharged from hospital and inadequate monitoring of noncollection of prescriptions. Most patients had a positive perception of the safety of their practice although $45 \%$ identified at least one safety problem in the past year.

From the *NIHR Greater Manchester Primary Care Patient Safety Translational Research Centre, University of Manchester; $†$ Centre for Primary Care, Division of Population Health, Manchester Academic Health Science Centre, University of Manchester, Manchester, United Kingdom; $₫$ Centre for Research and Action in Public Health (CeRAPH), University of Canberra, Bruce, Australian Capital Territory, Australia; §Division of Primary Care, School of Medicine, University of Nottingham Medical School, Queen's Medical Centre, Nottingham; ||Health Services Research Unit, Guy Hilton Research Centre, Keele University, Stokeon-Trent; Institute of Applied Health Research, College of Medical and Dental Sciences, University of Birmingham, Birmingham; **68 Brighton Cottages, Copyhold Lane, Lindfield, Haywards Heath, West Sussex; † † Nuffield Department of Primary Care Health Sciences, University of Oxford, Radcliffe Observatory Quarter, Oxford; $\$$ School of Medicine, Pharmacy, and Health, Holliday Building (C132), Durham University, Stockton-on-Tees, Durham; §§Primary Medical Care, University of Southampton, ||||Primary Care and Population Sciences, University of Southampton, Southampton; $\mathbf{\uparrow}$ Health Services and Policy Research Group, University of Exeter Medical School, Exeter; and *** Medical School, Teviot Place, The University of Edinburgh, Midlothian, United Kingdom.

Correspondence: Brian G. Bell, PhD, 1313 Tower Bldg, University of

Nottingham, Nottingham, NG7 2RD (e-mail: brian.bell@nottingham.ac.uk). The authors disclose no conflict of interest.

This work was funded by the National Institute for Health Research School for Primary Care Research.

The views expressed are those of the author(s) and not necessarily those of the National Institute for Health Research School for Primary Care Research, the National Health Service, or the Department of Health.

Supplemental digital contents are available for this article. Direct URL citations appear in the printed text and are provided in the HTML and PDF versions of this article on the journal's Web site (www.journalpatientsafety.com).

Copyright (C) 2018 The Author(s). Published by Wolters Kluwer Health, Inc. This is an open-access article distributed under the terms of the Creative Commons Attribution-Non Commercial-No Derivatives License 4.0 (CCBY-NC-ND), where it is permissible to download and share the work provided it is properly cited. The work cannot be changed in any way or used commercially without permission from the journal.
Conclusions: Patient safety is complex and multidimensional. The Patient Safety Toolkit is easy to use and hosted on a single platform with a collection of tools generating practical and actionable information. It enables family practices to identify safety deficits that they can review and change procedures to improve their patient safety across a key sets of patient safety issues.

Key Words: primary care, patient safety, safety climate

(J Patient Saf 2018;00: 00-00)

P atient safety has been defined as the "avoidance, prevention, and amelioration of adverse outcomes or injuries stemming from the processes of health care,"1 although it is a complex, multidimensional concept that is lacking an agreed operational definition in family practice. It encompasses many different dimensions, including diagnostic and prescribing safety, communication (both within and between practices and with other healthcare settings), organizational safety culture, and patient reported problems. ${ }^{2}$

Most healthcare interactions occur in family practice, for example, 340 million consultations being made annually in England. ${ }^{3}$ Most of the literature on patient safety has focused on hospitalbased services. $^{2}$ However, patient safety incidents occur in $2 \%$ to $3 \%$ of all clinical encounters. ${ }^{4}$

Family practice is thought of wrongly as inherently low risk, so safety is sometimes not considered a critical problem. ${ }^{5}$ However, serious errors leading to morbidity and mortality occur regularly in family practice. ${ }^{6}$ Understanding the epidemiology of hospital errors proved crucial for improving safety in hospitals, ${ }^{7}$ and there needs to be a similar focus on primary care. It is important to know to measure patient safety in primary care. ${ }^{8}$ Although there are multiple tools ${ }^{2}$ and some have substantial literatures, they are in isolation and not in a user-friendly single platform.

Moreover, there are major gaps in our understanding of primary care patient safety. ${ }^{4}$ A major review of research between 2000 and 2010 found virtually no credible studies on how to improve safety in primary care. ${ }^{9}$ To improve safety, one needs to be able to monitor and measure it. ${ }^{10}$

The National Institute for Health Research School for Primary Care Research funded us to develop and evaluate a Patient Safety Toolkit for English family practices. This article presents the quantitative results from the use of the Patient Safety Toolkit in a representative sample of English general practices to demonstrate the range of tools available to practices that can be found in one toolkit and the patient safety issues that were identified. The development of the toolkit has been presented elsewhere. ${ }^{2,11-13}$

\section{METHODS}

\section{Recruitment of Family Practices}

After obtaining ethical approval from Nottingham1 REC (13/ EM/0258) on July 31,2013 , an e-mail was sent to GP practices via their local National Institute for Health Research Primary Care 
Research Network to ask whether they wanted to be involved in the study. If the practice replied, a meeting was arranged with the respondent who was sent a recruitment pack to discuss the project and answer any questions. Participants who withdrew were not replaced in the analysis. Data were collected from June 2014 to April 2015.

We recruited 46 practices (10 in Birmingham, 8 in Keele, 8 in Manchester, 10 in the East Midlands, and 10 in Southampton) with 25 of these practices (10 in Birmingham, 5 in Keele, and 10 in Southampton) also recruited to collect data on the prescribing safety indicators. Practices were recruited to be representative of English family practices in terms of practice size, demographic characteristics of the practice population, whether the practices were involved in GP training, and Quality and Outcomes Framework scores. ${ }^{14}$

Each participant was assigned a code number for use on case report forms, which were used to collect data from each participating site, other study documents, and the electronic database. Some of the tools, such as the National Health Service (NHS) Education for Scotland Trigger Tool, ${ }^{15}$ required that clinicians from each practice examine patient notes, but no patient identifiable information was fed back to the research team.

\section{Testing of Toolkit Measures}

Six tools were tested based on the development of the Patient Safety Toolkit. ${ }^{10,11}$ Table 1 provides an overview of the tools. Descriptions of the tools are provided in Appendix 1, http://links. lww.com/JPS/A145. Staff in participating practices was asked to focus on specific tools in the toolkit rather than the full tool kit to spread the workload equally between practices. In each case, practical step-by-step methodologies for using each tool accompanied the relevant tool.

\section{NHS Education for Scotland Trigger Tool}

The trigger tool was used in 32 practices. Clinicians in these practices undertook electronic searches of their clinical computer systems to identify patients older than 75 years with "triggers," whose records were then reviewed to identify any patients who had been harmed. Clinicians recorded their findings and reported the results to the study team after removing patient identifiable information.

\section{Primary Care Safequest}

The Primary Care Safequest (PC-Safequest) is an online, anonymized questionnaire completed by members of the general practice staff. It was completed by 335 staff members from 31 practices. Demographic characteristics of the respondents, such as sex, whether they worked part-time or full-time, and their role within the practice, were collected. After completing the questionnaire, each practice generated a report that gave the practice's score on the five dimensions of safety climate. Practice staff then discussed the report at a team meeting.

\section{NHS Education for Scotland Medicines Reconciliation Tool}

This tool was tested in 16 practices. Practices undertook an audit of the records of up to 20 patients ${ }^{18}$ after hospital discharge to assess how promptly and how accurately medication changes suggested by the hospital had been made and whether the changes had been discussed with patients. Anonymized data were collected based on these audits.

\section{Patient Reported Experiences and Outcomes of Safety in Primary Care}

A total of 6736 questionnaires were sent to 45 practices, with 1244 questionnaires returned. Analyses were conducted at the patient level and were based on individual items. Inverse probability weights, related to likelihood of response, were applied in the analysis to produce results more representative of the full practice populations, not just the patients who participated. For each practice, data were extracted on the sex and age distributions of the patients registered, and separate sex and age probability weights were computed for each practice. The sex and age weights were then multiplied and rescaled for the weighted samples to match the practice list sizes. In general, weighted results did not substantially differ from unweighted results.

\section{Concise Safe Systems Checklist}

Eight practices in Keele completed the Concise Safe Systems Checklist, which consisted of nine items that assessed potential gaps in safety in general practice. Staff members were asked to complete the checklist for the practice as a whole, not for their individual role, and consider whether they were satisfied with the safety of the systems as implemented by their practice.

\section{Prescribing Safety Indicators}

We implemented the PINCER Query Library in family practices in the Birmingham and Southampton areas of England $(n=14)$. Computerized searches were run in the participating practices, and patients who were considered "at risk" were highlighted. For each of the prescribing safety indicators, the number and percentage of patients considered at risk were identified. Anonymized results were uploaded to CHART Online, and aggregated views were made available to practices and clinical care groups. We also

TABLE 1. Description of Patient Safety Tools Tested

\begin{tabular}{|c|c|c|}
\hline Tool & What Is Measured & No. Practices Recruited/Used Tool \\
\hline The NHS Education for Scotland Trigger Tool ${ }^{15,16}$ & $\begin{array}{l}\text { A system of rapid retrospective note review that } \\
\text { identifies triggers in samples of practices and } \\
\text { then identifies patients at risk of harm }\end{array}$ & 46 recruited $/ 32$ used $70 \%$ participation \\
\hline PC-Safequest ${ }^{17}$ & Measures safety climate & 38 recruited $/ 31$ used $82 \%$ participation \\
\hline $\begin{array}{l}\text { The NHS Education for Scotland Medicines } \\
\text { Reconciliation Tool }{ }^{18}\end{array}$ & $\begin{array}{l}\text { Measures safety of interface between primary } \\
\text { and secondary care following a patient's } \\
\text { discharge from hospital }\end{array}$ & 18 recruited $/ 16$ used $89 \%$ participation \\
\hline $\begin{array}{l}\text { Patient Reported Experiences and Outcomes of } \\
\text { Safety in Primary Care (PREOS-PC) }\end{array}$ & $\begin{array}{l}\text { Measures patient reported experiences and } \\
\text { outcomes in primary care }\end{array}$ & 46 recruited $/ 45$ used $98 \%$ participation \\
\hline Safe Systems Checklist & $\begin{array}{l}\text { Assesses aspects of patient safety not covered } \\
\text { by other tools }\end{array}$ & 8 recruited $/ 8$ used $100 \%$ participation \\
\hline Prescribing Safety Indicators ${ }^{21,22}$ & $\begin{array}{l}\text { Identifies patients at risk of medication error so } \\
\text { that prescribing problems can be tackled before } \\
\text { patients come to harm. }\end{array}$ & 25 recruited/14 used $56 \%$ participation \\
\hline
\end{tabular}


undertook a qualitative study to investigate the views of primary care staff on the Patient Safety Toolkit and their experiences of implementing the tools. The detailed results of the qualitative study are not reported here, but some summary findings are provided.

\section{RESULTS}

The practice characteristics for all of the practices and for the practices that completed each tool are provided in Table 2. The practices were reasonably representative, although our sample practices had more registered patients than the English mean and had a larger percentage of nonwhite patients.

\section{NHS Education for Scotland Trigger Tool}

Most of the triggers $(71 \%)$ fell into one of the following three categories: (1) three or more consultations in 7 days, (2) new significant diagnosis, or (3) out-of-hours/A\&E attendance (Appendix 1, Table A, http://links.lww.com/JPS/A145). The harm scores for the trigger tool reveal that more than a quarter of the events $(n=35$, $27 \%$ ) were considered likely to cause moderate or substantial harm. Thirty-eight percent of the events $(n=49)$ were considered potentially preventable and to have originated in primary care.

\section{Primary Care Safequest}

The mean scores ranged from 4 to 6 , which means that staff members generally thought that their practices had a moderately well-developed safety climate (scale score of 4 ) or achieved a well-developed safety climate to a "considerable" (scale score of 5) or "great" (scale score of 6) extent (Appendix 1, Table B, http://links.lww.com/JPS/A145). Appendix 1, Table C, http:// links.lww.com/JPS/A145, provides the intraclass correlations coefficients and reliability coefficients for the PC-Safequest scales. The intraclass correlations coefficients revealed little clustering within practices for the Communication and Safety Systems scales, which are poorer at discriminating between practices than the other scales. The practice mean reliability coefficients were all less than
0.7, which meant that none of the PC-Safequest scale scores met the accepted standard for reliability.

\section{National Health Service Education for Scotland Medicines Reconciliation tool}

Appendix 1, Table D, http://links.lww.com/JPS/A145 shows the percentage of "yes" responses to the six questions that comprise this tool; $85 \%$ of medicines reconciliation occurred within 2 days. However, discussions with the patient or carer did not occur $53 \%$ of the time even though such a discussion was considered clinically necessary more frequently than this (57\%).

\section{Patient Reported Experiences and Outcomes of Safety in Primary Care}

Results from the Patient Reported Experiences and Outcomes of Safety in Primary Care (PREOS-PC) questionnaire are detailed elsewhere. ${ }^{19,20}$ We received responses from 1244 patients (response rate $=18.4 \%$ ). As noted earlier, because of the use of weighted percentages (weighted by sex and age), 1244 patients form the denominator of all percentages that follow. Participants had a positive perception of the overall safety of their practice, with a mean (SE) score of $8.5(0.2)$ points out of 10 points on a visual analog scale, and with $91 \%(n=1,072)$ of them agreeing that their providers were trustworthy.

However, a total of 479 patients (45\%) reported having experienced at least one safety problem with the healthcare provided in their practices in the previous 12 months. Most frequently reported problems were related to appointments $(33 \%, \mathrm{n}=353)$, diagnosis $(17 \%)$, patient-provider communication $(15 \%)$, coordination between professionals in the practice $(14 \%)$, coordination between professionals from different settings (11\%), and problems with medication (4\%).

A total of 221 patients $(23 \%)$ reported having been harmed as a result of the healthcare provided by their practice in the previous 12 months, mostly in the form of anxiety or stress problems $(18.5 \%, \mathrm{n}=147)$, limitations in social activities $(14 \%)$, and pain $(11 \%)$.

TABLE 2. Practice Characteristics Mean (SD) for Practices

\begin{tabular}{|c|c|c|c|c|c|c|c|}
\hline & List Size* & $<18 y^{*}$ & $65+y^{*}$ & $\%$ Nonwhite $^{\dagger}$ & Deprivation Score* & QOF Score (2013)* & $\%$ Female $^{\dagger}$ \\
\hline \multirow[t]{2}{*}{ All practices (46 practices) } & 8751 & $20.2 \%$ & $15.7 \%$ & $17.6 \%$ & 22.1 & 971.3 & $51.1 \%$ \\
\hline & $(6218)$ & $(4.7 \%)$ & $(7.4 \%)$ & $(22.2 \%)$ & $(12.1)$ & $(30.5)$ & $(5.0 \%)$ \\
\hline Trigger tool & 10,031 & $19.7 \%$ & $15.7 \%$ & $14.6 \%$ & 19.8 & 971.9 & $52.0 \%$ \\
\hline (32 practices) & $(6800)$ & $(4.0 \%)$ & $(7.7 \%)$ & $(17.8 \%)$ & $(10.6)$ & $(29.0)$ & $(4.1 \%)$ \\
\hline Safequest & 8444 & $21.2 \%$ & $16.9 \%$ & $16.0 \%$ & 22.7 & 973.5 & $51.0 \%$ \\
\hline (31 practices) & $(5019)$ & $(4.3 \%)$ & $(6.7 \%)$ & $(23.3 \%)$ & $(13.0)$ & $(26.3)$ & $(5.0 \%)$ \\
\hline Medicines & 11,235 & $19.0 \%$ & $13.4 \%$ & $20.2 \%$ & 23.7 & 970.2 & $51.2 \%$ \\
\hline Reconciliation (16 practices) & (7924) & $(4.7 \%)$ & $(8.8 \%)$ & $(20.9 \%)$ & $(10.3)$ & $(18.4)$ & $(5.0 \%)$ \\
\hline PREOS-PC & 8744 & $20.4 \%$ & $15.4 \%$ & $18.0 \%$ & 22.4 & 973.3 & $51.0 \%$ \\
\hline (45 practices) & $(6288)$ & $(4.6 \%)$ & $(7.3 \%)$ & $(22.3 \%)$ & $(12.1)$ & $(27.7)$ & $(5.0 \%)$ \\
\hline Safe systems & 7363 & $20.7 \%$ & $19.5 \%$ & $13.1 \%$ & 22.5 & 988.1 & $52.9 \%$ \\
\hline Checklist (8 practices) & $(2830)$ & $(3.1 \%)$ & $(3.3 \%)$ & $(15.2 \%)$ & $(9.1)$ & $(7.6)$ & $(3.8 \%)$ \\
\hline Prescribing & 6623 & $19.7 \%$ & $18.6 \%$ & $17.3 \%$ & 21.7 & 972.8 & $49.4 \%$ \\
\hline Safety indicators (14 practices) & $(3535)$ & $(4.5 \%)$ & $(6.5 \%)$ & $(23.7 \%)$ & $(13.8)$ & $(33.3)$ & $(5.4 \%)$ \\
\hline English mean & $7041^{*}$ & $20.8 \% *$ & $16.7 \% *$ & $13 \%^{\dagger}$ & $21.5^{*}$ & $961^{*}$ & $51 \%{ }^{\dagger}$ \\
\hline
\end{tabular}

\footnotetext{
The practice mean and SD use values that are weighted by the practice list size.

*Taken from National General Practice Profiles (Public Health England) (http://www.apho.org.uk/PRACPROF/).

${ }^{\dagger}$ Taken from the GP Patient Survey July 2014 (http://www.practicetool.gp-patient.co.uk/practice).

QOF, Quality and Outcomes Framework.
} 


\section{Prescribing Safety Indicators}

Numbers (numerator/denominator and percentage) of patients identified as being at risk of medication error for each of the prescribing safety indicators are shown in Appendix 1, Table E, http://links. lww.com/JPS/A145. The eight prescribing safety indicators identified 1435 instances of potentially hazardous prescribing or lack of recommended monitoring in a total population of 92,649 patients. Compared with findings from the PINCER Trial, ${ }^{21}$ the proportion of patients identified at risk for each of the prescribing safety indicators was similar or lower, with the exception of the indicator relating to the monitoring of patients receiving warfarin, which was higher.

\section{Concise Safe Systems Checklist}

All of these practices closely matched the English mean as shown in Table 2. Appendix 1, Table F, http://links.lww.com/JPS/ A145 shows the responses to five of the checklist items, the other four items on the checklist exhibited ceiling effects with all of the respondents answering yes. Although most $(\geq 75 \%)$ of the respondents thought that their practices performed well, there is clearly room for improvement in two areas: (1) follow-up of vulnerable patients who were discharged from hospital and (2) noncollection of prescriptions.

\section{Summary of Qualitative Findings}

The concept of a balanced toolkit that used a combination of tools to address a range of safety issues proved popular with healthcare professionals and office staff. Tools that could be completed quickly and easily, such as the PC-SafeQuest survey and the Concise Safe Systems Checklist, were favored. Multiple competing demands on the practices meant that there was some reluctance to commit to using all aspects of the Toolkit on a regular basis.

\section{DISCUSSION}

We have described the use of a multiple tool Patient Safety Toolkit for measuring patient safety in family practices in England. The utility of the toolkit is that it covers a wide range of patient safety issues and is a collection of tools and knowledge that enables practice staff to monitor and measure and hence improve safety and effective care to patients. The Patient Safety Toolkit serves also as a general guide to applying safety improvement methods in family practice settings. The tools enable practice staff to create baselines and ongoing sets of data regarding patient safety using common methodologies and provide evidence at both a personal (GP revalidation and appraisal) and practice (care quality commission) level on the safety of care in the practice. This will support organizational learning and good practice and offers a practical way for practices to show their commitment to the measuring and monitoring of patient safety, ${ }^{8}$ while also motivating the staff who delivers the care. Such team-based learning enables practice teams to implement evidence-based patient safety tools and turn their ideas into best practice and safer outcomes. ${ }^{23}$

Practice staff reported that their practice had at least a moderately well-developed safety climate using the PC-Safequest tool. Safety climate refers to the perceived value placed on safety in an organization by those who work there. However, the Patient Safety Toolkit identified safety deficits using its range of tools that allowed practice staff to review and change procedures to improve patient safety.

The trigger tool identified undetected patient harm. It revealed that $27 \%$ of events found in patient records were associated with moderate or substantial harm and that $38 \%$ were potentially preventable and thought to have originated in primary care. This study confirms the utility of the Trigger Tool in English family practices, in keeping with findings from Scotland. ${ }^{24}$
The NHS Education for Scotland Medicines Reconciliation Tool showed that discussions with the patient or carer did not always occur when considered clinically necessary. Cresswell et $\mathrm{al}^{25}$ noted that communication between patients and health professionals was a source of patient safety incidents if health professionals do not engage in collaborative communication. ${ }^{26}$

The PREOS-PC showed that patients had a positive perception of the overall safety of their practice. However, almost half reported at least one safety problem in the last 12 months. ${ }^{27}$ The most frequently reported problem was with appointments and access to care and reinforced the fact that patients focus on a wider range of issues when making evaluations of the safety of the care they receive and perceive to be available. ${ }^{28}$ Moreover, we measured whether a problem had occurred but did not appraise the potential severity of such problems. This inclusive approach may have resulted in the identification of a substantial number of minor problems.

There are a complex series of transitions and interfaces along the patient journey. ${ }^{29}$ Information exchange, coordination, and communication among providers and organizations across these interfaces underpin many patient safety issues. ${ }^{30}$ The Concise Safe Systems Checklist revealed that although most of the respondents thought that their practice performed well, there are safety deficits in the follow-up of vulnerable patients discharged from hospital and how the practice deals with the noncollection of prescriptions. ${ }^{31}$

Prescribing errors are common in English general practice, although severe errors are unusual at approximately $0.2 \% .^{32,33}$ The prescribing safety indicators identified 1435 instances of potentially hazardous prescribing or lack of recommended monitoring in a total population of 92,649 patients. The value of prescribing safety indicators is that they improve safety by identifying patients at risk in order that prescribing problems can be tackled before patients come to any harm. ${ }^{34}$

\section{CONCLUSIONS}

One of the strengths of our toolkit is that it addresses safety deficits highlighted in the patient safety literature, such as prescribing and coordination and data flow between and among providers. The toolkit has used or adapted Scottish tools for assessing safety in primary care, which are available freely through the NHS Scotland Web site. ${ }^{15,18}$ It addresses gaps in the literature by using new tools, such as the PREOS-PC and the Concise Safe Systems Checklist, although some areas, such as diagnostic error, have been neglected in the literature, which means that the toolkit is not comprehensive.

A recent report by the National Patient Safety Foundation in the United States concluded that "little is known about the epidemiology of patient safety in settings outside of hospitals and about potential strategies for improvement, even though most care is delivered in these settings." 35 The Patient Safety Toolkit includes a range of safety tools in an accessible format that allows practice staff to measure and identify many facets of patient safety in family practices.

Making care in family practice settings safer requires a range of skills to measure and monitor safety that requires both usable information and the ability to use that information to identify and implement appropriate changes in care. The Patient Safety Toolkit is designed to assist family practice staff to develop and apply these skills using easy-to-use tools hosted on a single-site platform.

The Royal College of General Practitioners, funded by the NIHR Greater Manchester Primary Care Patient Safety Translational Research Centre, hosts an online version of the toolkit as part of their "Spotlight Projects," which gives clinicians globally access to the toolkit: http://www.rcgp.org.uk/clinical-and-research/ toolkits/patient-safety.aspx. This will help general practice staff monitor and improve patient safety. Future work could further establish the reliability and validity of the various tools and determine 
whether the routine use of the toolkit results in improvements in patient safety in family practice.

\section{REFERENCES}

1. National Patient Safety Foundation. Patient Safety Dictionary. Available at: $\mathrm{http} / / /$ www.npsf.org/?page=dictionarynz\&hhSearchTerms $=\% 22$ avoidance $\% 2 c+$ prevention $\% 2 c+$ and + amelioration+of+adverse $\% 22$. Accessed August 15, 2015.

2. Spencer R, Campbell S. Tools for primary care patient safety; a narrative review. BMC Fam Pract. 2014;15:166.

3. British Medical Association. Quality First: Managing workload to deliver safe patient care. January 2015. Available at: http://bma.org.uk/practicalsupport-at-work/gp-practices/quality-first. Accessed February 17, 2015.

4. Panesar SS, Carson-Stevens A, Cresswell KM, et al. How safe is primary care? A systematic review. BMJ Qual Saf. 2015;25:544-53.

5. Sheikh A, Panesar SS, Larizgoitia I, et al. Safer primary care for all: a global imperative. Lancet Glob Health. 2013;1:e182-e183.

6. Dovey SM, Meyers DS, Phillips RL, et al. A preliminary taxonomy of medical errors in family practice. Qual Saf Health Care. 2002;11:233-238.

7. Avery AJ, Barber N, Ghaleb M, et al. Investigating the prevalence and causes of prescribing errors in general practice: the PRACtICe study. 2012.

8. Vincent C, Burnett S, Carthey J. Health Foundation Spotlight report, April 2013 'The Measurement and Monitoring of Safety'. Available at: http:// www.health.org.uk/publications/the-measurement-and-monitoring-ofsafety. Accessed July 13, 2017.

9. Wynia MK, Classen DC. Improving ambulatory patient safety: learning from the last decade, moving ahead in the next. JAMA. 2011;306: 2504-2505.

10. Campbell SM, Kontopantelis E, Hannon KL, et al. Framework and indicator testing protocol for developing and piloting quality indicators for the UK quality and outcomes framework. BMC Fam Pract. 2011;12:85.

11. Bell BG, Spencer R, Avery AJ, et al. Tools for measuring patient safety in primary care settings using the RAND/UCLA appropriateness method. BMC Fam Pract. 2014;15:110.

12. Ricci-Cabello I, Avery AJ, Reeves D, et al. Measuring patient safety in primary care: the development and validation of the "Patient Reported Experiences and Outcomes of Safety in Primary Care" (PREOS-PC). Ann Fam Med. 2016;14:253-261.

13. PRIMIS. The University of Nottingham. Available at: http://www.primis. nottingham.ac.uk/index.php/services/information/chart. Accessed August 17, 2015.

14. Health and Social Care Information Centre. Quality and Outcomes Framework GP Practice Results. Available at: http://qof.hscic.gov.uk/. Accessed August 17, 2015.

15. Scottish Patient Safety Programme. Trigger Tool. Healthcare Improvement Scotland. NHS Scotland. Available at: http://www. scottishpatientsafetyprogramme.scot.nhs.uk/programmes/primary-care/ safety-culture. Accessed August 15, 2015.

16. DeWet $C$, Bowie $P$. The preliminary development and testing of a global trigger tool to detect error and patient harm in primary-care records. Postgrad Med J. 2009;85:176-180.

17. De Wet C, Spence W, Mash R, et al. The development and psychometric evaluation of a safety climate measure for primary care. Qual Saf Health Care. 2010;19:578-584.

18. Scottish Patient Safety Programme. Medicines Reconciliation Care Bundle. Healthcare Improvement Scotland. NHS Scotland. Available at: http:// www.scottishpatientsafetyprogramme.scot.nhs.uk/programmes/ primary-care/safer-medicines. Accessed August 15, 2015.

19. Ricci-Cabello I, Goncalves DC, Valderas JM. Development of a measure of patient reported experiences and outcomes of patient safety in general practices in England: the PREOS-PC instrument. Quality of Life Research. 2013;22 1 Supplement, Abstracts Presented at the 20th Annual Conference of the International Society for Quality of Life Research.

20. Ricci-Cabello I, Marsden K, Avery AJ, et al. Patients' evaluations of patient safety in English general practices: a cross-sectional study. Br J Gen Pract. 2017;67:e474-e482.

21. Avery A, Rodgers S, Cantrill J, et al. Pharmacist-led information technology-enabled intervention for reducing medication errors: multi-centre cluster randomised controlled trial and cost-effectiveness analysis (PINCER Trial) Lancet. 2012;379:1310-1319.

22. Spencer R, Bell B, Avery AJ, et al. Identification of an updated set of prescribing-safety indicators for GPs. Brit J Gen Pract. 2014;64: e181-e190.

23. Leonard M, Graham S, Bonacum D. The human factor: the critical importance of effective teamwork and communication in providing safe care. Qual Saf Health Care. 2004;13(suppl 1):i85-i90.

24. De Wet C, Black C, Luty S, et al. Implementation of the trigger review method in Scottish general practices: patient safety outcomes and potential for quality improvement. BMJ Qual Saf. 2017;26:335-342.

25. Cresswell KM, Panesar SS, Salvilla SA. Global research priorities to better understand the burden of iatrogenic harm in primary care: an international Delphi exercise. PLoS Med. 2013;10:e1001554.

26. Stevenson FA, Cox K, Britten N, et al. A systematic review of the research on communication between patients and health care professionals about medicines: the consequences for concordance. Health Expect. 2004;7: 235-245.

27. Rhodes P, McDonald R, Campbell S, et al. Sensemaking and the co-production of safety: a qualitative study of primary medical care patients. Sociol Health Illn. 2016;38:270-285.

28. Rhodes P, Campbell S, Sanders C. Trust, temporality and systems: how do patients understand patient safety in primary care? A qualitative study. Health Expect. 2016;19:253-263.

29. Vincent C, Amalberti R. The ideal and the real. In: Vincent C, Amalberti R, eds. Safer Healthcare. Cham: Springer International Publishing; 2016: 13-25.

30. Romagnoli KM, Handler SM, Ligons FM, et al. Home-care nurses' perceptions of unmet information needs and communication difficulties of older patients in the immediate post-hospital discharge period. BMJ Qual Saf. 2013;22:324-332.

31. Tandjung R, Rosemann T, Badertscher N. Gaps in continuity of care at the interface between primary care and specialized care: general practitioners' experiences and expectations. Int J Gen Med. 2011;4:773-778.

32. Stocks SJ, Kontopantelis E, Akbarov A, et al. Examining variations in prescribing safety in UK general practice: cross sectional study using the Clinical Practice Research Datalink. BMJ. 2015;351:h5501.

33. Avery AJ, Ghaleb M, Barber N, et al. The prevalence and nature of prescribing and monitoring errors in English general practice: a retrospective case note review. Br J Gen Pract. 2013;63:e543-e553.

34. Avery AJ, Rodgers S, Franklin BD, et al. Research into practice: safe prescribing. Br J Gen Pract. 2014;64:259-261.

35. National Patient Safety Foundation. Free from Harm: Accelerating Patient Safety Improvement Fifteen Years After To Err Is Human. Boston:National Patient Safety Foundation, 2015. 